\title{
Accident Tolerant Fuel Analysis
}

Principal Investigator:

Curtis Smith

Contributors:

Heather Chichester

Jesse Johns

Melissa Teague

Michael Tonks

Robert Youngblood

September 2014

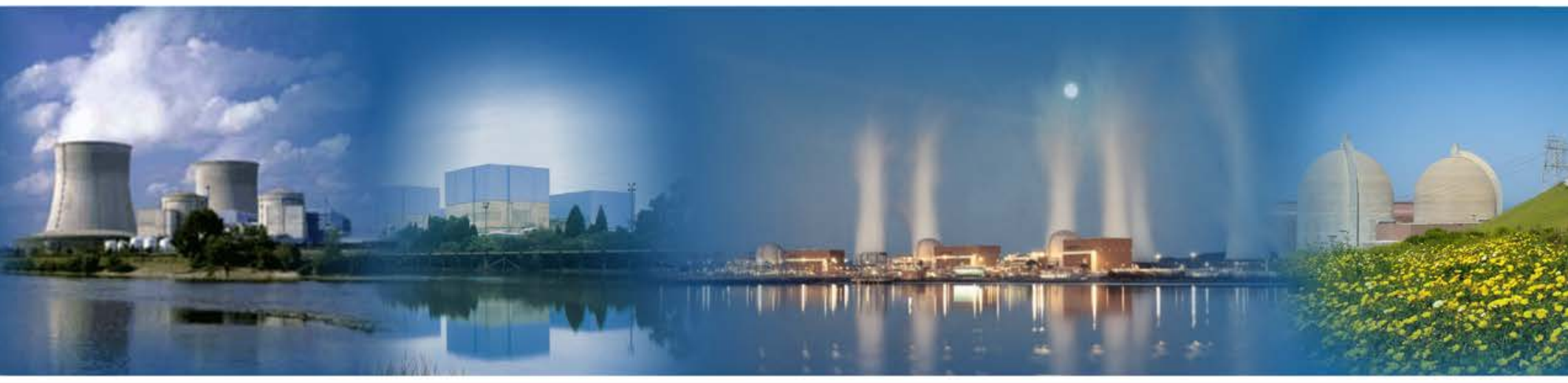

U.S. Department of Energy Office of Nuclear Energy 


\section{DISCLAIMER}

This information was prepared as an account of work sponsored by an agency of the U.S. Government. Neither the U.S. Government nor any agency thereof, nor any of their employees, makes any warranty, expressed or implied, or assumes any legal liability or responsibility for the accuracy, completeness, or usefulness, of any information, apparatus, product, or process disclosed, or represents that its use would not infringe privately owned rights. References herein to any specific commercial product, process, or service by trade name, trade mark, manufacturer, or otherwise, does not necessarily constitute or imply its endorsement, recommendation, or favoring by the U.S. Government or any agency thereof. The views and opinions of authors expressed herein do not necessarily state or reflect those of the U.S. Government or any agency thereof. 


\section{Accident Tolerant Fuel Analysis}

September 2014

Idaho National Laboratory Idaho Falls, Idaho 83415

http://www.inl.gov

Prepared for the

U.S. Department of Energy

Office of Nuclear Energy

Under DOE Idaho Operations Office

Contract DE-AC07-05ID14517 



\section{EXECUTIVE SUMMARY}

Safety is central to the design, licensing, operation, and economics of Nuclear Power Plants (NPPs). Consequently, the ability to better characterize and quantify safety margin holds the key to improved decision making about light water reactor design, operation, and plant life extension. A systematic approach to characterization of safety margins and the subsequent margins management options represents a vital input to the licensee and regulatory analysis and decision making that will be involved.

The purpose of the Risk Informed Safety Margin Characterization (RISMC) Pathway research and development (R\&D) is to support plant decisions for risk-informed margins management by improving economics and reliability, and sustaining safety, of current NPPs. Goals of the RISMC Pathway are twofold: (1) Develop and demonstrate a risk-assessment method coupled to safety margin quantification that can be used by NPP decision makers as part of their margin recovery strategies. (2) Create an advanced "RISMC toolkit" that enables more accurate representation of NPP safety margin.

In order to carry out the R\&D needed for the Pathway, the Idaho National Laboratory is performing a series of case studies that will explore methods- and tools-development issues, in addition to being of current interest in their own right. One such study is a comparative analysis of safety margins of plants using different fuel cladding types: specifically, a comparison between current-technology Zircaloy cladding and a notional "accident-tolerant" (e.g., SiC-based) cladding. The present report begins the process of applying capabilities that are still under development to the problem of assessing new fuel designs.

The approach and lessons learned from this case study will be included in future Technical Basis Guides produced by the RISMC Pathway. These guides will be the mechanism for developing the specifications for RISMC tools and for defining how plant decision makers should propose and evaluate margin recovery strategies. 


\section{CONTENTS}

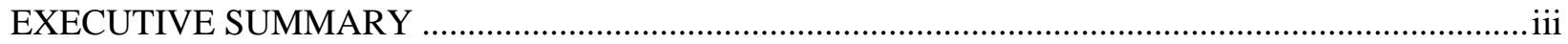

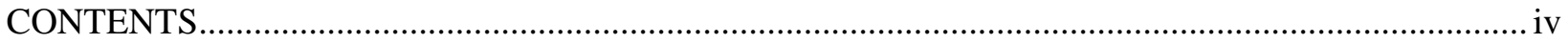

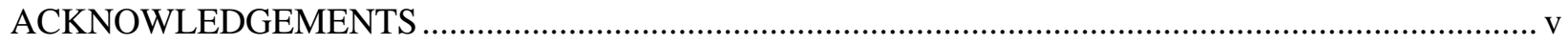

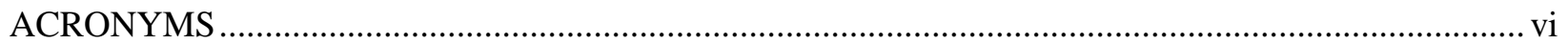

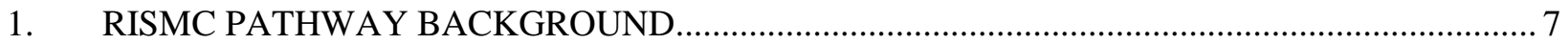

2. BACKGROUND ON PREVIOUS ANALYSIS OF CLADDING …....................................... 9

2.1 Basis for Original Regulatory Acceptance Criteria........................................................... 9

2.2 Recently-Proposed Rulemaking on Regulatory Acceptance Criteria .................................. 9

2.3 Preliminary Modeling of Behavior of Candidate Accident-Tolerant Fuel in Severe

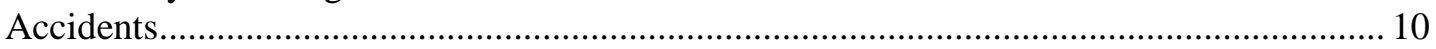

2.4 Preliminary Comparison of Zircaloy-clad Fuel with Hypothetical “Accident-

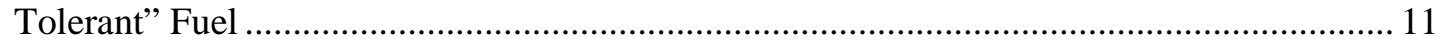

3. PRELIMINARY LOCA SENSITIVITY ANALYSIS FOR NOTIONAL ATF ........................... 12

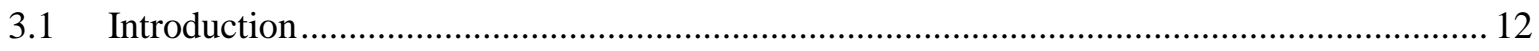

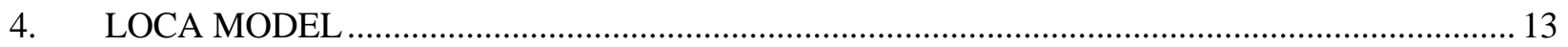

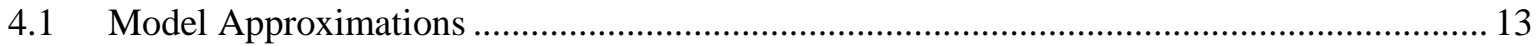

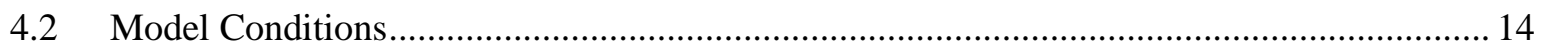

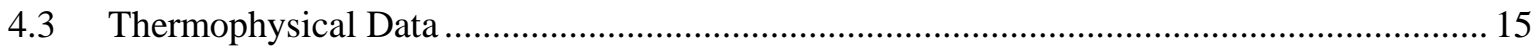

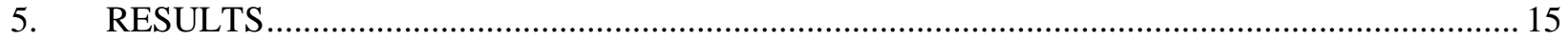

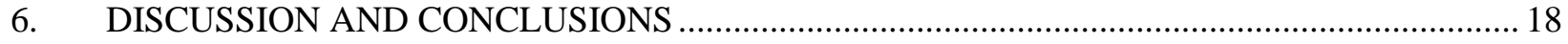

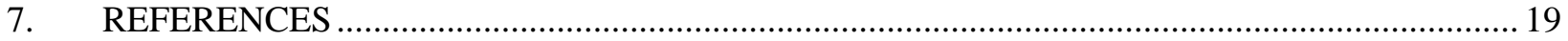




\section{ACKNOWLEDGEMENTS}

In addition to having been informed by several years of work in the Risk-Informed Safety Margin Characterization Pathway within the Light Water Reactor Sustainability Program, this report has benefited from several discussions with Shannon Bragg-Sitton on the subject of her work for the Advanced Fuels Campaign. We are also grateful to the BISON and RAVEN teams for their help in implementation. 


\section{ACRONYMS}

$\begin{array}{ll}\text { ATF } & \text { Accident-Tolerant Fuel } \\ \text { DOE } & \text { Department of Energy } \\ \text { DB } & \text { Design Basis } \\ \text { ECCS } & \text { Emergency Core Cooling System } \\ \text { FMEA } & \text { Failure Modes \& Effects Analysis } \\ \text { INL } & \text { Idaho National Laboratory } \\ \text { LWR } & \text { light water reactor } \\ \text { LWRS } & \text { light water reactor sustainability } \\ \text { NPP } & \text { nuclear power plant } \\ \text { NRC } & \text { Nuclear Regulatory Commission } \\ \text { PIRT } & \text { Phenomena Identification \& Ranking Table } \\ \text { PRA } & \text { probabilistic risk assessment } \\ \text { R\&D } & \text { research and development } \\ \text { RISMC } & \text { Risk Informed Safety Margin Characterization } \\ \text { Si } & \text { Silicon Carbide } \\ \text { SSC } & \text { system, structure, and component } \\ \text { T-H } & \text { thermal-hydraulics }\end{array}$




\section{RISMC PATHWAY BACKGROUND}

Safety is central to the design, licensing, operation, and economics of nuclear power plants (NPPs). As the current light water reactor (LWR) NPPs age beyond 60 years, there are possibilities for increased frequency of systems, structures, and components (SSC) degradations or failures that initiate safetysignificant events, reduce existing accident mitigation capabilities, or create new failure modes. Plant designers commonly "over-design" portions of NPPs and provide robustness in the form of redundant and diverse engineered safety features to ensure that, even in the case of well-beyond design basis scenarios, public health and safety will be protected with a very high degree of assurance. This form of defense-indepth is a reasoned response to uncertainties and is often referred to generically as "safety margin."

The ability to better characterize and quantify safety margin holds the key to improved decision making about LWR design, operation, and plant life extension. A systematic approach to characterization of safety margin and the subsequent margin management options represents a vital input to the licensee and regulatory analysis and decision making that will be involved. In addition, as research and development (R\&D) in the LWR Sustainability (LWRS) Program and other collaborative efforts yield new data, sensors, and improved scientific understanding of physical processes that govern the aging and degradation of plant SSCs (and concurrently support technological advances in nuclear reactor fuels and plant instrumentation and control systems) needs and opportunities to better optimize plant safety and performance will become known. This interaction of degradation understanding and potential impacts to plant margins is shown in Figure 1. To support decision making related to economics, readability, and safety, the RISMC Pathway [1] provides methods and tools that enable mitigation options known as margins management strategies.

The purpose of the RISMC Pathway R\&D is to support plant decisions for risk-informed margin management with the aim to improve economics, reliability, and sustain safety of current NPPs. As the lead Department of Energy (DOE) Laboratory for this Pathway, the Idaho National Laboratory (INL) is tasked with developing and deploying methods and tools that support the quantification and management of safety margin and uncertainty.

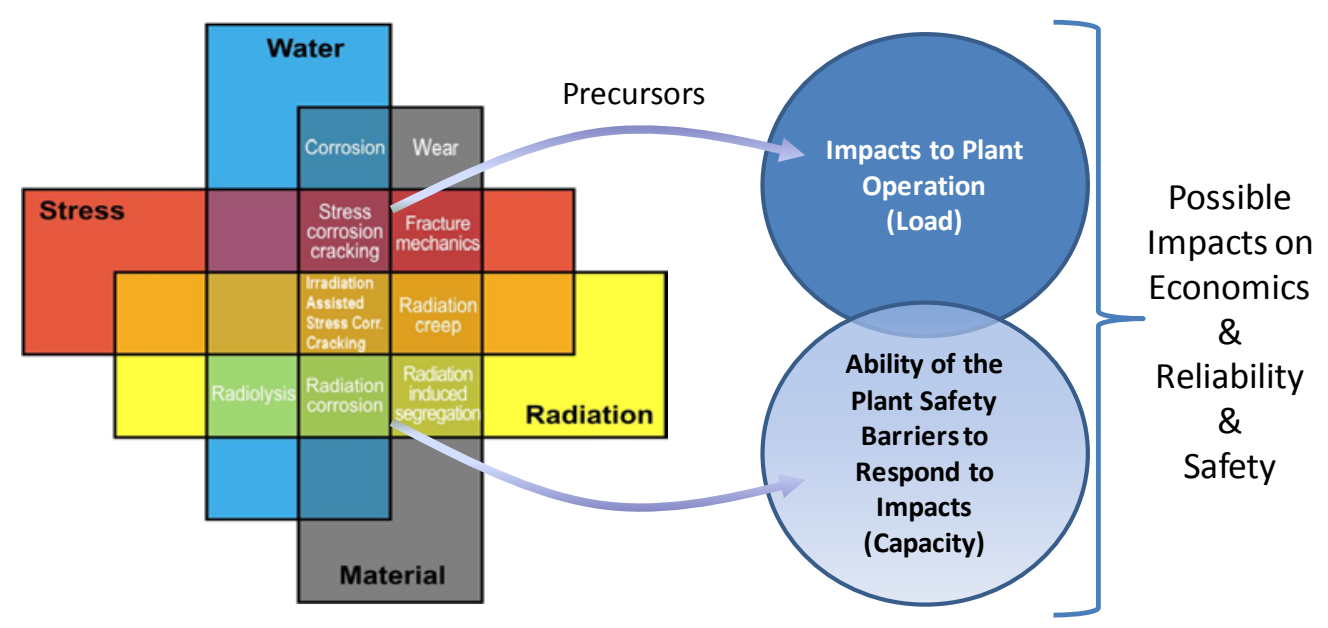

Figure 1. Representation of the interaction of degradation mechanisms that may impact plant operations and safety barriers if left unmitigated.

Goals of the RISMC Pathway are twofold:

1. Develop and demonstrate a risk-assessment method coupled to safety margin quantification that can be used by NPP decision makers as part of their margin recovery strategies. 
2. Create an advanced "RISMC toolkit" that enables more accurate representation of NPP safety margin.

One of the primary goals of the Pathway is to develop the capability to propose and evaluate margin recovery strategies (i.e., proposed changes to SSCs or plant procedures that work to mitigate margin degradation due to aging or plant modifications, including margin enhancement in some areas to compensate for degradation in others). If a plant safety margin is degraded, the RISMC methods and tools will help to model, measure, and maintain compensating margins in other active and passive SSCs for normal and off-normal conditions. Moving beyond current limitations in safety analysis, the Pathway will develop techniques to conduct analysis using simulation-based studies of safety margins where "margin" go beyond the typical engineering margins concept. For example, licensing margins as a part of the plant's design basis are not the only ones protecting the public; plant safety also depends on margins that are not necessarily analyzed in licensing.

The INL approach to the research and development needed for the RISMC Pathway is based on a series of case studies that serve to focus development of tools and methodology, in addition to being of interest in their own right. One such case study is a margins-based comparison of the behavior of Zircaloy cladding with new cladding designs based on silicon carbide (SiC). Zircaloy cladding works well under normal conditions, but it is well known that loss of core cooling can lead to core melt, with release of radioactive material into containment, as occurred at Three Mile Island in 1979 [2], and release of radioactive material from containment, as occurred at Fukushima in 2011[3]. In addition to loss of the fuel cladding barrier in these accidents, a significant amount of combustible hydrogen was also produced, leading to additional damage and affecting the release of radioactive material at Fukushima. The behavior of $\mathrm{SiC}$ at corresponding temperatures seems to be more robust than the behavior of Zircaloy, suggesting that cladding using SiC might have significantly enhanced margin to failure in loss-of-cooling scenarios. However, the comparison must consider multiple attributes in multiple scenario types. A predecessor report [4] discussed the analysis needed to support such a study.

The original intention of the present task to evaluate ATF performance during FY14 was to use the Idaho National Laboratory's recently developed modeling and simulation tools:

- MOOSE- The Multiphysics Object-Oriented Simulation Environment [5] is a finite-element, multiphysics framework. It provides a high-level interface to sophisticated nonlinear solver technology, and is provides the framework upon which other analysis tools are created.

- $\quad$ BISON - BISON [6] is a finite element-based nuclear fuel performance code applicable to a wide variety of fuel forms. It solves the fully-coupled equations of thermomechanics and species diffusion, for either 1D spherical, 2D axisymmetric or 3D geometries. BISON development is underway to support accident analysis, specifically LOCAs. The code is currently being used to investigate a variety of ATF design concepts.

- RAVEN - The Risk Analysis Virtual ENvironment [7] is a controller that provides the capability to model systems, structures, and components using both steady-state and dynamic control of a scenario evolution. The controlling capability is based on a software structure that realizes a direct connection between various MOOSE-based modules. RAVEN supports the generation of scenario control by supplying a wide range of probabilistic models.

BISON is an analysis tool (still under development) that simulates in-reactor fuel behavior; MOOSE is an environment within which codes such as BISON operate; RAVEN is a controller that (when completed and documented) will allow a user to drive BISON (when completed) to explore fuel performance within a user-defined issue space.

The reader is referred to [6] for a discussion of BISON. For present purposes, the key point is that despite the implication of the present task statement, the capability to analyze fuel behavior in realistic accident situations is still under development and not yet available to users, even if a prospective user had 
a reasonable set of fuel design parameter values and materials properties to use as input to BISON, which is also presently a hurdle.

Given existing BISON capability, what can presently be done to add value to the ATF effort, and to lay a foundation for future RISMC contributions to that effort, is to conduct a parametric study of the behavior of hypothetical fuels in environments that apply some of the loads that a real accident would impose. While highly simplified relative to what needs to be done eventually, this study can shed light on how certain attributes play out under accident stress, an analysis task that is complicated by virtue of the potential complexity of the actual behavior for a given set of fuel properties, some of which complexity can be studied even with present capability.

This study is described in Section 3.

\section{BACKGROUND ON PREVIOUS ANALYSIS OF CLADDING}

\subsection{Basis for Original Regulatory Acceptance Criteria}

A useful summary of the original technical basis for current regulatory acceptance criteria for accident analysis emergency core cooling system (ECCS) performance of LWRs is contained in [8]. That reference reconstructs the reasoning behind the current acceptance criteria $\{<17 \%$ oxidation AND $<2200$ F peak clad temperature\}. The Commission (at that time, the Atomic Energy Commission) considered it important to maintain coolable geometry of the core, both during an accident and for a long time thereafter. Among other things, this meant that the fuel should not shatter, either as a result of stresses imposed during the accident or stresses imposed during subsequent fuel handling. This meant that the fuel structure (specifically including the cladding) should remain ductile. Satisfaction of the oxidation and peak temperature criteria is meant to assure maintenance of ductility, whereas violation of either criterion creates a potential for loss of ductility. It is additionally explained in [8] that in order for the desired conclusion regarding ductility to be supportable, the analysis needed to apply the Baker-Just correlation.

These acceptance criteria are very different from the criteria applied in risk analysis, as will be illustrated in Section 2.3. Probabilistic risk analysis for nuclear power plants is usually implicitly about exposure of the public to releases of radioactive material in the course of core melt accidents, and for that purpose, different (more lenient) failure criteria are applicable. However, the current regulatory acceptance criteria are not "conservative" relative to the regulatory concern being addressed. (In fact, as discussed in [8], they are non-conservative for high-burnup fuel.) Maintaining fuel integrity during and after accidents arguably needs to be considered in the margins-informed comparison of cladding merits.

\subsection{Recently-Proposed Rulemaking on Regulatory Acceptance Criteria}

Recently, work sponsored by the Nuclear Regulatory Commission (NRC) suggested that the current regulatory acceptance criteria are actually non-conservative for higher-burnup fuel: that there exist embrittlement mechanisms not contemplated in the original criteria, and that the $17 \%$ limit on oxidation is not adequate to preserve the level of ductility that the Commission originally deemed to be warranted for adequate protection. At this writing, a rulemaking is being contemplated to address several points, including this one. Excerpts from a relevant Commission paper [8] are provided below.

Information developed through the NRC's high burnup fuel research program has identified that the current criterion for preventing fuel cladding embrittlement may not be adequate to ensure the health and safety of the public. As discussed in Sections II and V of this Statement of Considerations, zirconium-based alloy fuel cladding materials may be subject to embrittlement at a lower combination of temperature and level of oxygen absorption (17 percent) than currently allowed under $\S$

50.46(b)(1) due to absorption of hydrogen during normal operation. The proposed rule would correct 
those limits initially established to prevent embrittlement of zirconium-based alloy cladding material based on the new research information. In addition, the research work has identified new phenomena, such as breakaway oxidation and oxygen diffusion from the cladding inside surfaces, which are believed to further adversely affect the fuel cladding embrittlement process. Thus, post quench ductility (which is necessary to ensure coolable core geometry) ${ }^{3}$ is not guaranteed following a postulated LOCA. The proposed rule would establish new requirements for zirconium-based alloys to prevent breakaway oxidation and account for oxygen diffusion from the oxide fuel pellet during the operating life of the fuel. In sum, the NRC believes that imposing the requirements of the proposed rule is necessary to prevent embrittlement of fuel cladding and to restore the rule to the level of reasonable assurance of adequate protection to public health and safety.

3 The Commission concluded, as part of the 1973 Emergency Core Cooling System rulemaking, that retention of ductility in the zircaloy cladding material was determined to be the best guarantee of its remaining intact during the hypothetical loss-of-coolant accident, thereby maintaining a coolable core geometry. See Acceptance Criteria for Emergency Core Cooling Systems for Light-WaterCooled Nuclear Power Reactors, CLI-73-39, at page 1098 (December 28, 1973).

$\cdots$

With respect to current nuclear power plant licensees, the NRC assumes that imposition of the proposed rule would constitute backfitting as defined in § 50.109(a)(1). However, the NRC believes that the proposed rule must be imposed upon current nuclear power plant licensees in order to ensure adequate protection to the public health and safety by restoring that level of protection (i.e., reasonable assurance of adequate protection) which the NRC thought would be achieved (throughout the entire term of licensed operation) by the current rule. Therefore, the NRC has determined that the proposed rule is necessary to ensure that the facility provides adequate protection to the health and safety of the public, and that a backfit analysis as described in $\S \S 50.109(a)(3)$ and (b) need not be prepared under the exception in § 50.109(a)(4)(ii).

For present purposes, the key points are the following.

- Cladding performance cannot be evaluated in isolation. Cladding performance and ECCS performance need to be considered together.

- Models for cladding performance even within the design basis will need to be updated for regulatory purposes and for purposes of this case study.

- Effort needs to be expended in searching the regulatory issue space for the limiting case. This has always been clear, but now it is explicit, and there may be more stringent reporting requirements on the analysis ("ECCS performance must be demonstrated for a range of postulated loss-ofcoolant accidents of different sizes, locations, and other properties, sufficient to provide assurance that the most severe postulated loss-of-coolant accidents have been identified. ECCS performance must be demonstrated for the accident, and the post-accident recovery and recirculation period." [8])

\subsection{Preliminary Modeling of Behavior of Candidate Accident- Tolerant Fuel in Severe Accidents}

Severe accidents have been modeled extensively since TMI. In NRC guidance, an accident is "severe" if it is more severe than an event within the design basis. [9] For operating LWRs using today's cladding, an accident is arguably "severe" if a significant amount of hydrogen is evolved, whether or not the core itself completely loses geometry, because that large amount of hydrogen is beyond the design basis. 
A recent paper by Merrill and Bragg-Sitton (reference [10]) compares the behavior of Zircaloy with a notional version of SiC cladding in a "TMI event." The comparison is based on MELCOR simulations, and used MELCOR failure criteria for fuel, which are based on loss of geometry during the accident, and do not consider the regulatory acceptance criterion discussed above. The assumed event progression matches what happened at TMI from an active component point of view: in the simulation, pumps start and stop at the exact same time they started and stopped in the actual event, valves open and close in the simulation as they did in the event, and so on.

The figures below are taken from [10], which presented two simulations of the "TMI event," one with Zircaloy and one with SiC. Figure 2 below (Figure 5 of reference [10]) shows that the temperature behavior of the Zircaloy run is very different from the temperature behavior of the SiC run. But since decay heat and the timing and rates of injection are the same in the two cases, the temperature difference is due largely to differences in the cladding-water reaction. Those reactions are the focus of Figure 6 of reference [10] (Figure 3 below). Note that the vertical axis is a log scale. It is seen that sometimes the Zrwater reaction contributes significantly more heat than decay heat contributes, and much more than the oxidation heating associated with $\mathrm{SiC}$ contributes.

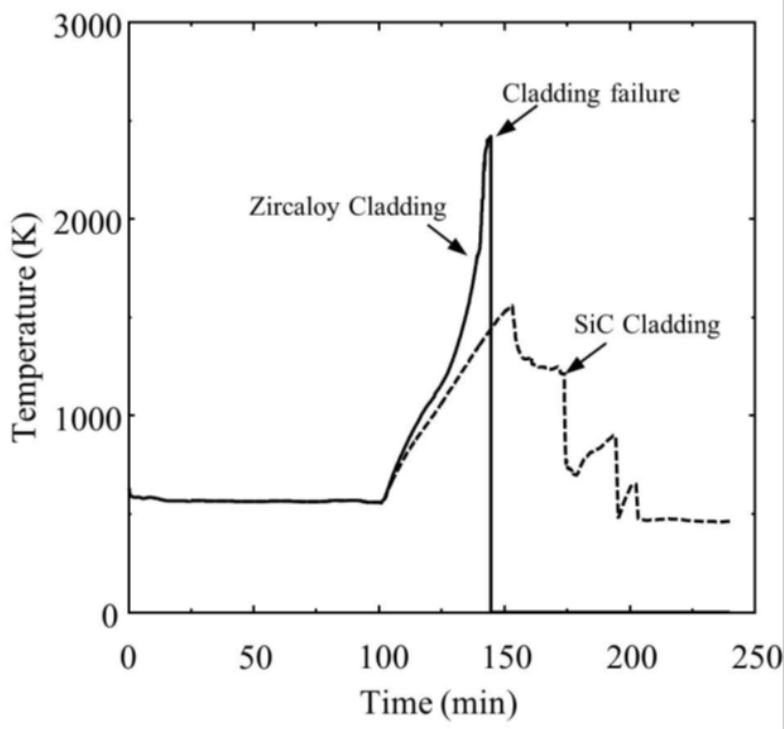

Figure 2. (Figure 5 of [10]) Comparison of MELCOR predicted maximum cladding temperature during a TMI-2 accident.

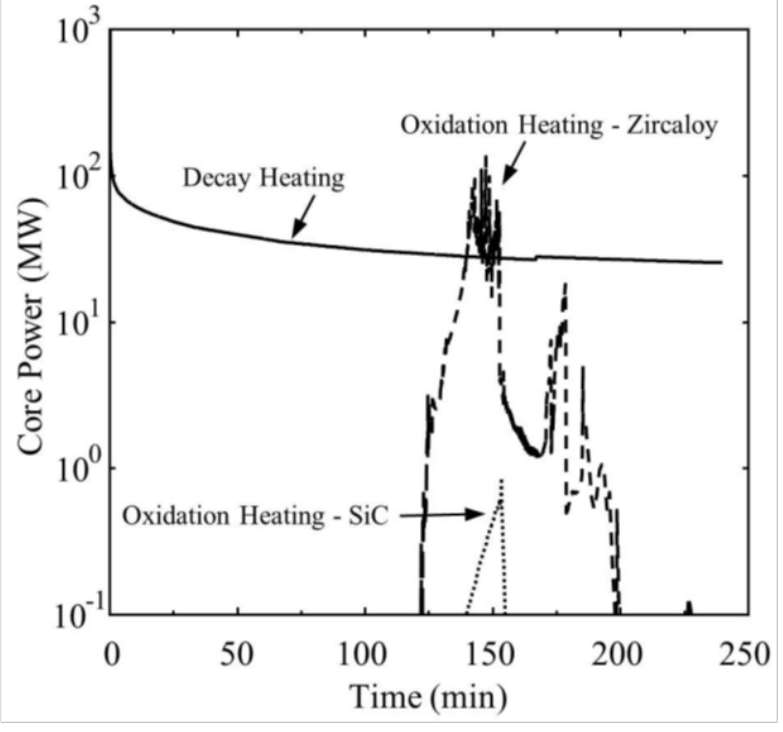

Figure 3. (Figure 6 of [10]) Comparison of MELCOR predicted clad oxidation heating produced during a TMI-2 accident.

Pros and cons of this comparison are discussed in a later subsection. The comparison is suggestive, and carries the point that a SiC model has been implemented in MELCOR, but was not carried out in a way that would comprehensively support a technology downselect.

\subsection{Preliminary Comparison of Zircaloy-clad Fuel with Hypothetical "Accident-Tolerant" Fuel}

Note: This subsection paraphrases selected points made in a review draft of [11] prepared by BraggSitton et al., which compares simulations of plant behavior in selected severe-accident scenarios assuming today's fuel cladding with simulations assuming notional "accident-tolerant” fuel (ATF) cladding.

It is inappropriate to furnish details of those predecisional discussions in the present report. However, simulations performed for that report furnish instances of certain general points made here, and moreover 
have driven certain details in the formulation of the detailed case study steps enumerated in a later section of the present report, which beneficial influence is hereby acknowledged.

Selected key points from [11]:

In the simulations involving ATF, very high temperatures are reached in some areas for some scenarios, in contrast to results for today's conventional fuel cladding. This occurs because in certain of the scenarios modeled, and given the modeling assumptions, today's fuel fails structurally and relocates to the lower portion of the vessel, while the ATF cases are modeled as retaining geometry. This raises two categories of issues:

Since some portions of the overall system experience harsher environments in the ATF case than in the conventional-cladding case, the comparison needs to treat carefully the question of which plant-level outcome is "better." In fact, which case is "better" might even depend on the duration of the loss of cooling.

The observation of very high temperatures in the ATF case reinforces the need to determine carefully which failure modes of what internal components are limiting in the ATF case that were NOT limiting with today's fuel cladding in the system.

The simulations done for [8] point to these issues, but the FMEA/PIRT exercises implied by them were beyond the scope of that effort. These steps are, however, called out in the process described later in Section 4.

\section{PRELIMINARY LOCA SENSITIVITY ANALYSIS FOR NOTIONAL ATF}

\subsection{Introduction}

The accident tolerant fuel (ATF) program at the Idaho National Laboratory (INL) is leveraging both experimental and computational capabilities to provide insight on the performance of novel fuel concepts for light water reactors (LWRs). This work is still in its early stages and data on the various ATF concepts is limited. However, info is needed on what cladding properties have the largest impact on the fuel performance, especially during accident conditions. This information is not available experimentally, but could be obtained using modeling and simulation.

Modern fuel performance codes, such as INL's BISON code, predict the fuel and cladding behavior in steady-state, transient, and accident conditions. This modeling capability could be a powerful tool in investigating the impact of cladding properties of the fuel performance. However, materials models for the new ATF concepts have not yet been developed. An approach to gain important insights into fuel performance without these models is to conduct a sensitivity study in which certain fuel and cladding properties are varied in a large number of simulation runs and certain critical behaviors are investigated as functions of those properties.

This short report demonstrates how such a sensitivity study can be conducted using the BISON fuel performance code [6] using a statistical uncertainty quantification tool such as INL's RAVEN [7] code or Sandia National Laboratory's (SNL's) DAKOTA [12] to manage the simulations and the resultant data. This study does not represent a comprehensive sensitivity analysis, but rather is a benchmarking study to show the main capabilities of a coupled RAVEN/DAKOTA framework with BISON. For the study, we use a simplified model of a loss of coolant accident (LOCA) event. Selected cladding properties are varied, and the resultant change in the clad stress is recorded. Results in this report are preliminary and demonstrations are performed with DAKOTA and BISON, using Python scripts for manual postprocessing.

BISON is an INL-developed fuel performance code based on the MOOSE framework, which provides a state-of-the-art finite-element computational foundation for developing fully-coupled physics 
models. This simulation environment is ideally suited for handling the complexity of fuel performance calculations. BISON has a wide-range of solid mechanics capabilities, from plastic deformation to solid/thermal contact. It includes models for irradiation and fission-product swelling, fission gas production and release, and burnup dependent thermophysical properties, to name a few. BISON solves the thermomechanical system of equations, capturing critical phenomena such as thermal and mechanical contact, fission gas release, and materials properties that are functions of burn-up defined by engineering models $^{\mathrm{a}}$. BISON can also be coupled with other MOOSE-based codes to replace some of these engineering models with physics models.

RAVEN is an INL-developed uncertainty/sensitivity analysis code that interacts with the MOOSE framework. While it is not strictly dependent on MOOSE, it leverages MOOSE libraries to implicitly couple with Relap-7 - the main focus of its development. However, RAVEN is general and can, therefore, be used to interface directly with the BISON code to run input cases with a large spectrum of capabilities. For example, the distribution function of a parameter can be set to follow any number of statistical distributions. This would be useful when determining the impact of fabrication variations, which are seen in some of the novel ATF cladding concepts. Another promising feature of RAVEN is the ability to generate limit surfaces. These structures use a defined failure criteria in order to assess limits on various parameters, given a known number of degrees of freedom, to maintain a success rate. In other words, this allows the user to determine, for example, if they have a smaller Young's modulus than expected by such an amount, how much the geometry or thermal expansion has to change in order to maintain a successful sample.

RAVEN employs the use of databases in order to greatly improve computational efficiency. The hdf5 database saves all the run-time data from BISON and the metaphysical data from RAVEN. This approach means simulations do not have to be re-run and even older simulations can continue to populate the knowledge phase-space of a database. Leveraging all this data can better inform surrogate models, which supply RAVEN with vast data fields to assess these limit surfaces.

DAKOTA is developed at SNL and is similar to RAVEN in that it can perform sensitivity and uncertainty analyses. However, it does not use a database and does not have built-in post processing tools. Here, it is used to build a preliminary population of simulations.

Performing these kinds of simulations allows fuel designers to have a more in-depth understanding of the variance and covariance of design decisions on the survivability on their ATF concepts during offnormal, server incidents. The approach of simulation-driven informed engineering optimizes the necessary experiments, saving time and money. In addition, if applied to a hierarchical system model, this approach can be used to assess the impact factor of these candidates across the spectrum of the fuel cycle.

\section{LOCA MODEL}

This section discusses the model conditions and approximations of the simplified LOCA model.

\subsection{Model Approximations}

A 2D, axial-symmetric geometry is used to represent the fuel and cladding. The gas gap and the coolant are not explicitly represented, but rather the heat transfer coefficient on both is determined with built-in engineering models. A smeared-pellet approximation is used to represent the fuel meat, such that individual pellets are not represented. Given the large number of simulations to be performed, this approximation is necessary to reduce the computational burden. Moreover, it is not expected that this will significantly impact the cladding performance results.

${ }^{a}$ An engineering model is an approximate representation of physical phenomena by a reduced-order fit to experimental data. 
There are a quite a few coupled-physics effects that impact the progression of a LOCA: the thermomechanical and thermochemical responses of the fuel and cladding contribute greatly to the outcome of the event. Currently, BISON is not capable of thermochemical modeling, so the range of events is limited, currently, to mechanical performance.

\subsection{Model Conditions}

The LOCA event is modeled by changing the mass flux and coolant pressure accordingly. Decay heat is represented in the fuel after shutdown. The following describes the LOCA event as modeled in BISON:

1. $(0<\mathrm{T}<555.6$ days $)$

Initialize fuel burnup and restructuring.

2. $\mathrm{T}_{\mathrm{o}}=555.6$ days

Begin LOCA

3. $\left(\mathrm{T}_{0}, \mathrm{~T}_{0}+3 \mathrm{~s}\right)$

Mass flux reduced linearly with time $(3800 \mathrm{~kg} / \mathrm{s}$-> $30 \mathrm{~kg} / \mathrm{s})$

4. $\left(\mathrm{T}_{\mathrm{o}}+2 \mathrm{~s}, \mathrm{~T}_{\mathrm{o}}+4 \mathrm{~s}\right)$

Reactor SCRAM initiated and power reduced to zero.

5. $\left(\mathrm{T}_{\mathrm{o}}+3 \mathrm{~s}, \mathrm{~T}_{\mathrm{o}}+6 \mathrm{~s}\right)$

Mass flux further reduced linearly $(30 \mathrm{k} / \mathrm{s}->3 \mathrm{~kg} / \mathrm{s})$

6. $\left(\mathrm{T}_{\mathrm{o}}+7 \mathrm{~s}, \mathrm{~T}_{\mathrm{o}}+30 \mathrm{~s}\right)$

Mass flux increased linearly with time $(3 \mathrm{~kg} / \mathrm{s}->400 \mathrm{~kg} / \mathrm{s})$

7. $\left(\mathrm{T}_{\mathrm{o}}+1 \mathrm{e} 5 \mathrm{~s}\right)$

Simulation completed.

The increase in mass flux in step 6 is to "end" the LOCA event. Without this occurrence, the simulation may not be able to converge due to the high strain rates and resulting large deformations. MOOSE is inherently an implicit finite element library and implicit finite element, while robust, cannot handle large mesh deformations. As the creep models and deformation capabilities of BISON mature, these simulations can be further expanded to more challenging LOCA cases.

A representative case of the conditions above is shown in Figure 4. This situation is not catastrophic for the cladding; however, it allows for general scoping of thermophysical properties without crashing most of the simulations. 

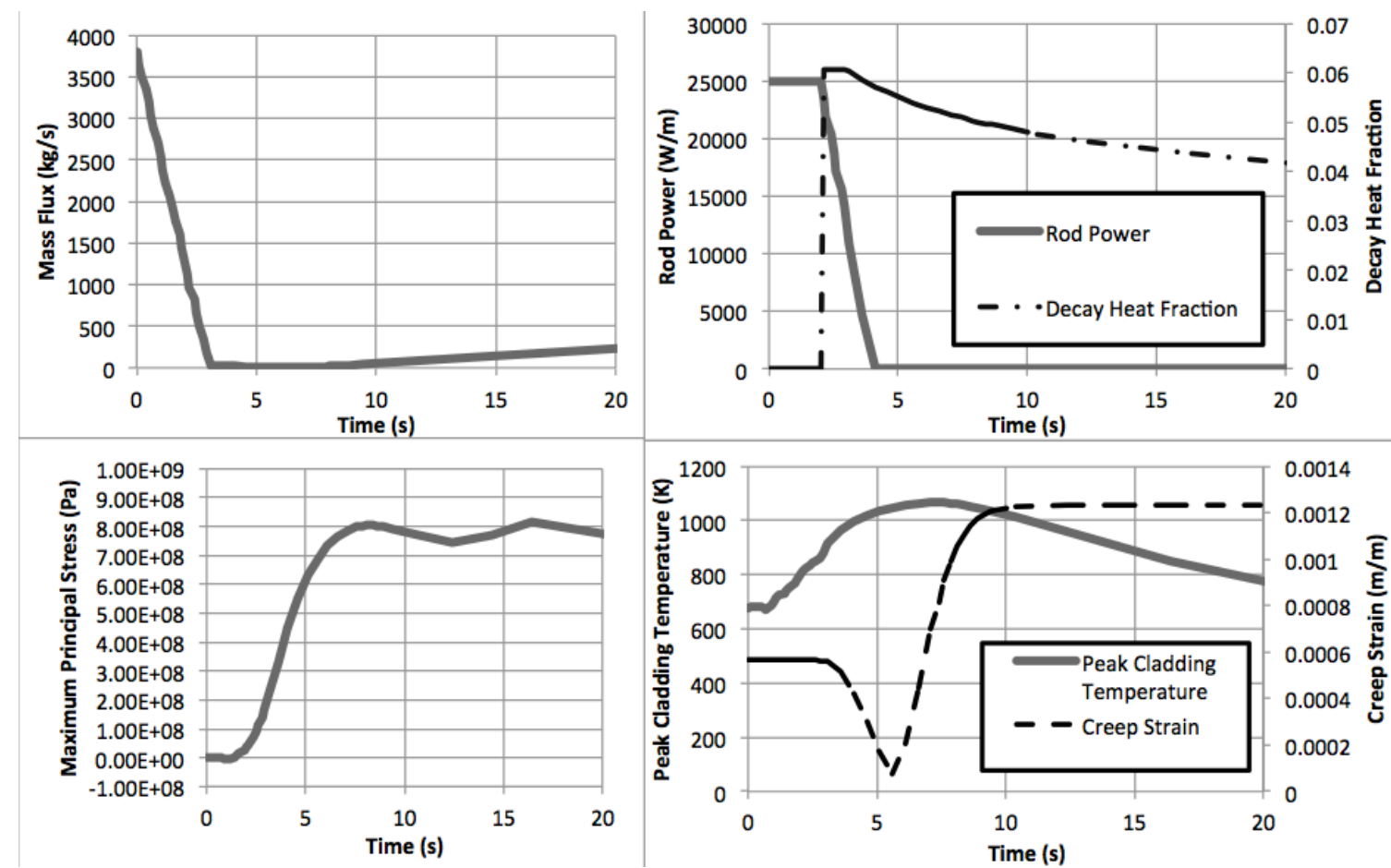

Figure 4. Results of a representative LOCA simulation. Simulations inputs are shown on top and the BISON results shown on the bottom.

\subsection{Thermophysical Data}

The thermophysical data for Zr4 and UO2 used in these simulations are built in with BISON. They can be referenced in the BISON theory manual.

\section{RESULTS}

In this parametric study, the following thermophysical parameters were altered:

1. Thermal conductivity

2. Specific heat capacity

3. Young's Modulus

4. Thermal expansion coefficient

Creep is the primary nonlinear deformation mechanism for most clad materials, and therefore would be an important factor to vary as well. However, creep models for different models vary by more than one parameter. Thus, creep does not lend itself to a simple parametric study like this one. Therefore, we used an empirical creep model for zircaloy cladding in all simulations. Future work will vary the creep model through various discrete options representing different candidate ATF claddings.

The following output parameters were tracked explicitly, though all run data was saved for future processing:

1. Maximum creep strain

2. Peak cladding temperature

3. Maximum principal stress

4. Maximum von Mises stress 
These simulations are demonstrated as a proof of principle, so a failure criterion is not yet specified for cladding performance evaluation. However, these results, as-is, can provide conceptual guidance for future selection.

To investigate the behavior shown by the analysis, we investigate the sensitivity of the creep strain, an indicator of the total plastic deformation that results from thermally induced creep. Figures 5, 6, 7, and 8 show the sensitivity for various thermophysical relationships. These plot the percent difference from the maximum value of each variable and the magnitude of the creep strain.

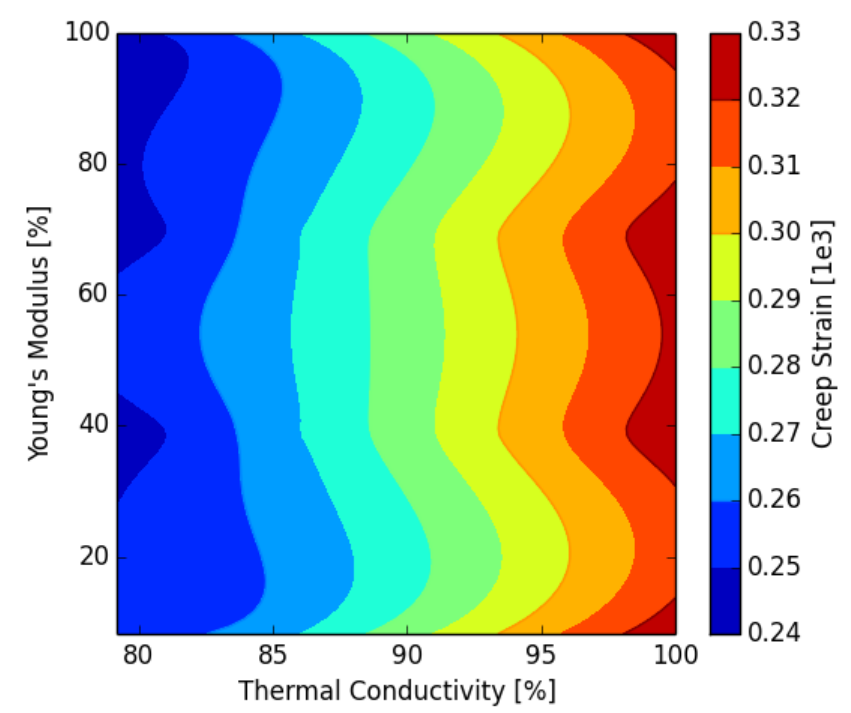

Figure 5. Creep strain as a function of thermal conductivity and Young's Modulus.

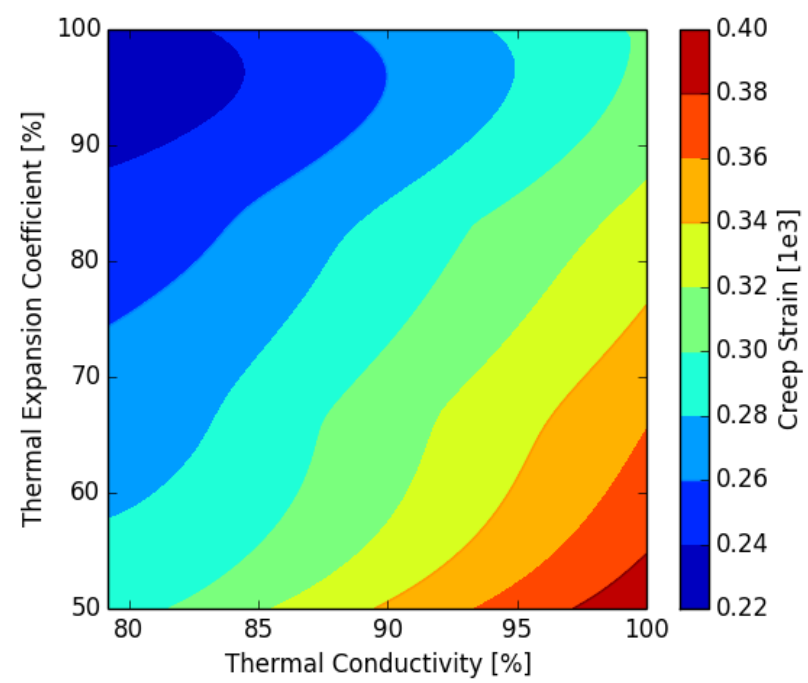

Figure 6. Creep strain as a function of thermal conductivity and thermal expansion coefficient. 


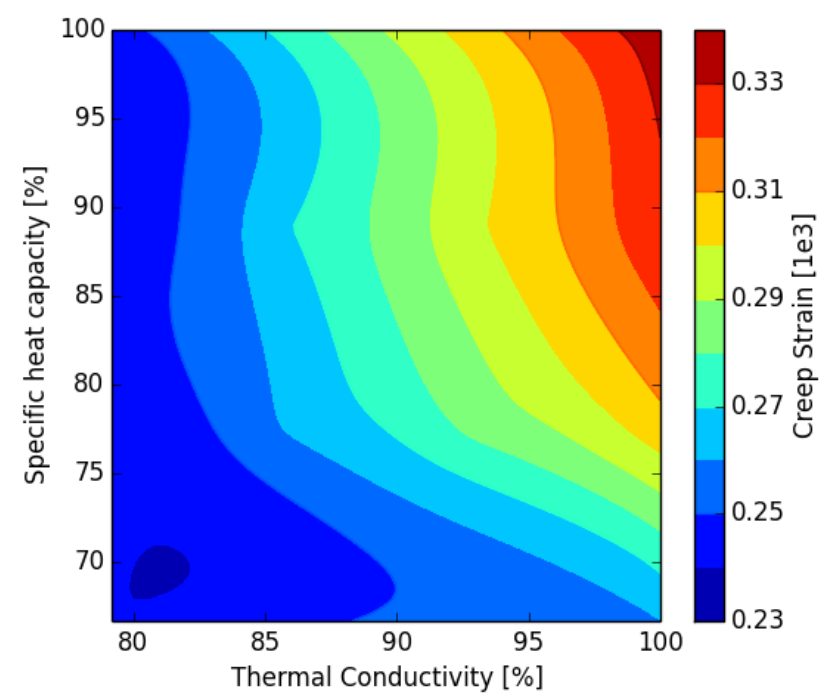

Figure 7. Creep strain as a function of thermal conductivity and specific heat capacity.

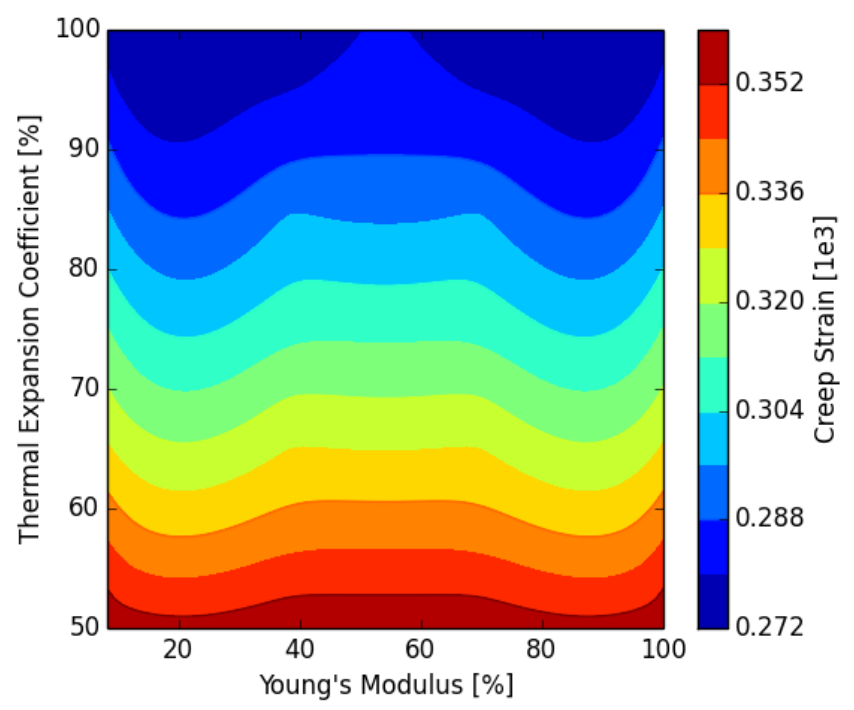

Figure 8. Creep strain as a function of Young's modulus and thermal expansion coefficient.

The contour plot lines were chosen for this representation because they assist in determining the relationship of variables with the parameter of interest. Gradients can be observed and calculated from the plot. Since the number of runs is relatively small, the interpolation error can be pretty high near the edges. However, overall trends are accurate.

There are several major trends that can be observed from these results. First, the creep strain is fairly insensitive to the Young's Modulus, as shown in Figure 8. The thermal expansion coefficient has a fairly linear effect on the creep strain, though there is some interaction with the thermal conductivity, i.e. the creep strain is more sensitive to the thermal expansion coefficient at high thermal conductivity. The most complicated interaction is found between the specific heat capacity and the thermal conductivity. The creep strain is insensitive to the specific heat at low thermal conductivity but highly sensitive at high thermal conductivity. Similarly, the creep strain is only slightly sensitive to the thermal conductivity at 
low specific heat, but highly sensitive at high specific heat. In effect, the cladding temperature responds more quickly to the introduction of coolant, which minimizes the impact of the short LOCA event.

The relationship between thermal expansion and thermal conductivity was expected to be non-linear, but it is apparently linear in this range.

Though this initial analysis was fairly successful, we did observe issues that need to be resolved in future work. When viewing the maximum principle stress, it appears an indices problem is occurring, see Figure 9. There is a saddle point in the maximum principal stress, when investigating the impact of thermal expansion coefficient and thermal conductivity. This behavior is consistent across all the data sets and may indicate an error in how the postprocessing data is being read.

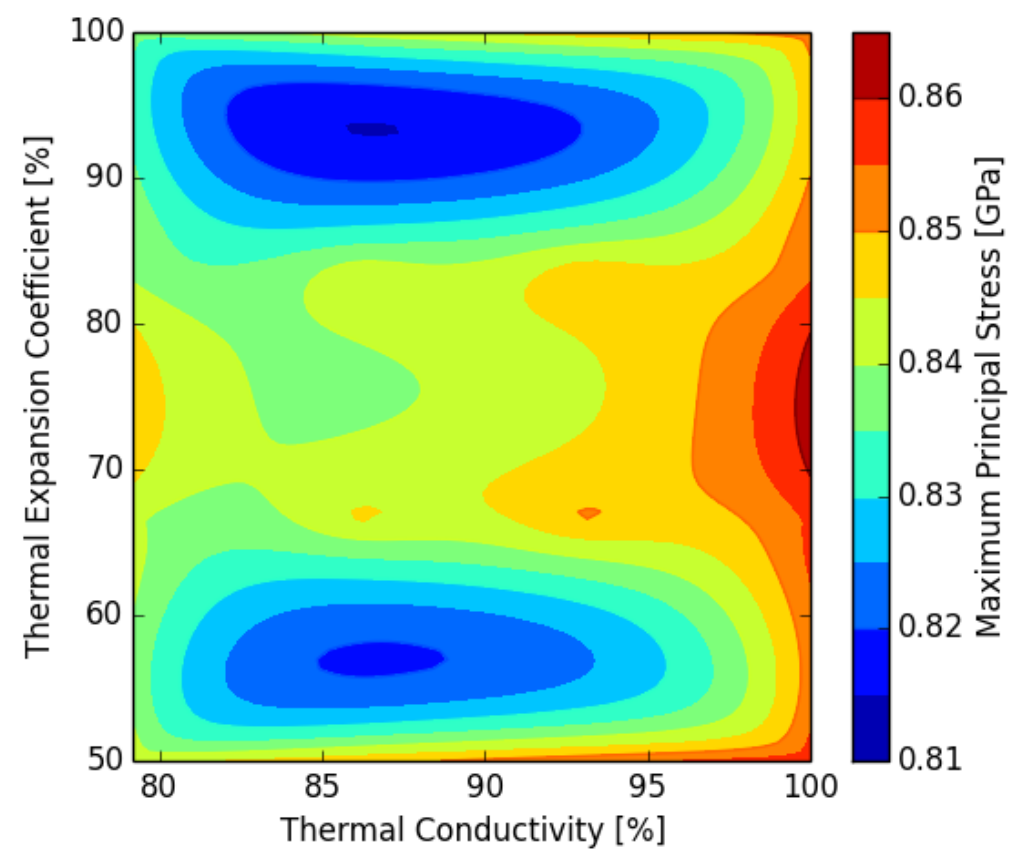

Figure 9. Maximum principle stress as a function of thermal conductivity and thermal expansion coefficient.

\section{DISCUSSION AND CONCLUSIONS}

This work has shown how the BISON code can be used with programs like DAKOTA or RAVEN to investigate the sensitivity of accident behavior to material properties. Though the LOCA model was simplified and we only investigated the sensitivity of cladding behavior to a few cladding properties, we can make some preliminary conclusions. The creep strain is minimized for large values of the thermal expansion coefficient, and small values of the thermal conductivity and the specific heat. The creep strain is most sensitive to the thermal conductivity and specific heat. Thus, new cladding materials that have a low thermal conductivity and a low specific heat will have the least creep strain.

While this work has shown the potential of this type of work, it was really only a proof of concept, and significant work remains to be completed. Some aspects of the approach need to be investigated in order to remove possible errors. In addition, the cladding creep behavior needs to be changed to discretely for different ATF cladding concepts. The LOCA model should be improved, adding multiphysics coupling to the coolant behavior and a more robust solution approach to allow the simulation to be run to higher clad deformation. Finally, fuel properties could be varied as well, to identify the most sensitive properties and to identify any interactions with cladding properties. 


\section{REFERENCES}

[1] Light Water Reactor Sustainability Program Integrated Program Plan, Revision 1, INL-EXT11-23452, April 2013.

[2] M. Rogovin et al., Three Mile Island: A Report to the Commissioners and to the Public, Nuclear Regulatory Commission special Inquiry Group (USNRC, 1980).

[3] Randall Gauntt et al., Fukushima Daiichi Accident Study (Status as of April 2012), SAND2012-6173 (SNL, 2012).

[4] R. Youngblood and C. Smith, Technical Approach and Results from the Fuels Pathway on an Alternative Selection Case Study, INL/EXT-13-30195 Revision 0, Idaho National Laboratory, September 2013.

[5] D. Gaston, C. Newman, G. Hansen, and D. Lebrun-Grandi'e. MOOSE: A parallel computational framework for coupled systems of nonlinear equations. Nucl. Eng. Design, 239:1768-1778, 2009.

[6] J. D. Hales, S. R. Novascone, G. Pastore, D. M. Perez, B. W. Spencer, R. L. Williamson, BISON Theory Manual (INL, 2013).

[7] RAVEN [A user document for RAVEN is in preparation at the time of this writing.]

[8] Proposed Rulemaking - 10 CFR 50.46c: Emergency Core Cooling System Performance During Loss-Of-Coolant Accidents (RIN 3150-AH42), R. W. Borchardt, SECY-12-0034 (NRC, March 1, 2012).

[9] "The Commission has developed guidance and goals for resolving those safety issues related to reactor accidents more severe than the design-basis accidents (DBAs). These "severe accidents" are those in which substantial damage is done to the reactor core, regardless of whether serious offsite consequences occur.” -- Final Safety Evaluation Report Related to Certification of the AP1000 Standard Design (NUREG-1793, Initial Report), Chapter 19.

[10] B. J. Merrill, and S. M. Bragg-Sitton, "SiC Modifications to MELCOR for Severe Accident Analysis Applications,” 2013 LWR Fuel Performance Meeting/TopFuel, American Nuclear Society, Charlotte, North Carolina, USA, September 15-19 (2013).

[11] Advanced Fuels Campaign: Light Water Reactor Accident Tolerant Fuel Performance Metrics, INL/EXT-13-29957, FCRD-FUEL-2013-000264, S. Bragg-Sitton et al., August 2013.

[12] Brian M. Adams et al., "Dakota, A Multilevel Parallel Object-Oriented Framework for Design Optimization, Parameter Estimation, Uncertainty Quantification, and Sensitivity Analysis,” Version 5.3 User’s Manual, SAND2010-2183 (updated February 13, 2013) (SNL, 2013). 